and range from $0.010^{\prime \prime}$ on the galactic equator to 0.024 " near the pole for stars of magnitude $9.0 \mathrm{~m} .-14.0 \mathrm{~m}$., and from $0.010^{\prime \prime}$ to $0.019^{\prime \prime}$ for magnitude $14 \cdot 1 \mathrm{~m} .-15 \cdot 0 \mathrm{~m}$.

The stars of proper motion less than $0 \cdot 1^{\prime \prime}$ are collected and their distribution per square degree given for different galactic latitudes. The number of variable stars found is very small, being no more than one star in 2,900 .

The Radcliffe Observer and his staff are to be heartily congratulated on the conclusion of this laborious and useful piece of work.

F. W. D.

\section{Rapid Physics}

Experimental Physics : a Selection of Experiments. By Dr. G. F. C. Searle. Pp. xiv +363. (Cambridge: At the University Press, 1934.) 16s. net.

$\mathbf{N}^{O N}$ cuivis homini contingit adire Corinthum; $N$ and those of us who have not been fortunate enough to have come directly under the influence of Searle's inspiring personality, owe him a heavy debt of gratitude for leaving us some record-incomplete though it may be-of the methods which he has practised with such eminent success for nigh fifty years.

It is an impressive record; all the more so in that this, his latest, although we hope not his last, volume shows all the vigour and energy and enthusiasm - and thank Heaven, the prejudicesthat have ever characterised his work. It has been called an "Odds and Ends Book", and never has there been a volume to which the term could be applied with less justification-singleness of purpose and outlook inform and penetrate every page.

Skill in design ; an uncanny aptitude for hitting on an experiment which will illustrate half a dozen physical principles; a remembrance of the saying that small corrections are the fun of physies; a consequent hunt for the fourth or fifth significant figure even when, Dulong-wise (or is it Petit-wise?), the third may be now and then in doubt; the aptitude of an accomplished craftsman for making the utmost use of simple mathematics; a violent dislike for tobacco-all the characteristics that we know and love are there.

The topics handled-do they really matter? Still, it is usually considered to be the reviewer's first task to give his readers some inkling of the contents of the book, and we have here a record of some thirty-four experiments, four or five being devoted to dynamics, six to elasticity, thirteen to surface tension and viscosity, five to heat, and five to sound. Each of the main sections is prefaced by a chapter dealing with the mathematical principles involved.
There is but one serious criticism to put forward, and that is concerned with a section of the preface which states that the author has "abandoned a former project of writing a manual on Experimental Electricity and Magnetism". We trust that the author will, in the comparative leisure that will fall to him after September 30, 1935, reconsider this decision. We have heard old Triton blow his wreathéd horn, and, after revelling in the heartening blasts which he has sounded, we love not the descent to the electrical-and-magnetic bleatings of more orthodox volumes. May he be persuaded to wind another strain, this time to the theme of electricity and magnetism! A.F.

\section{Reaction Kinetics}

The Reaction between Hydrogen and Oxygen. By C. N. Hinshelwood and Dr. A. T. Williamson. Pp. $\mathbf{v}+108$. (Oxford: Clarendon Press ; London: Oxford University Press, 1934.) $8 s .6 d$. net.

$\mathbf{W}^{\text {ITH }}$ the rapid development of science, it is very convenient to have in one's hand from time to time a critical and authoritative up-to-date monograph on the present status of some important phases in scientific development. Such an account is given by Mr. Hinshelwood and Dr. Williamson on the reaction between hydrogen and oxygen.

The more general implications of the chain mechanism advanced by Nernst to interpret the hydrogen chlorine reaction were pointed out and developed by Semenov, who, in his famous paper of 1927 on the phosphorus - oxygen reaction, not only referred to the hydrogen-oxygen reaction, but also indicated and afterwards investigated with his collaborators the phenomena of homogeneous slow combustion, rapid combustion, degenerate and true explosions, and interpreted the phenomena of upper and lower limits of ex. plosion. The view that such reactions are chain reactions entails an inquiry into the mechanism of the starting, propagation, reflection, branching and cessation of the chains as well as the factors operative in limiting the explosion both at the upper and lower limit. These reactions form not only an important connecting link between surface or heterogeneous catalytic actions and true homogeneous reactions, but also provide us with a means for obtaining, admittedly in small concentration, new and reactive chemical entities, the chain carriers.

It is generally admitted that the hypothesis of simple atomic links such as obtain in the reactions investigated by Polanyi is not adequate to interpret the experimental data in chain reactions such 